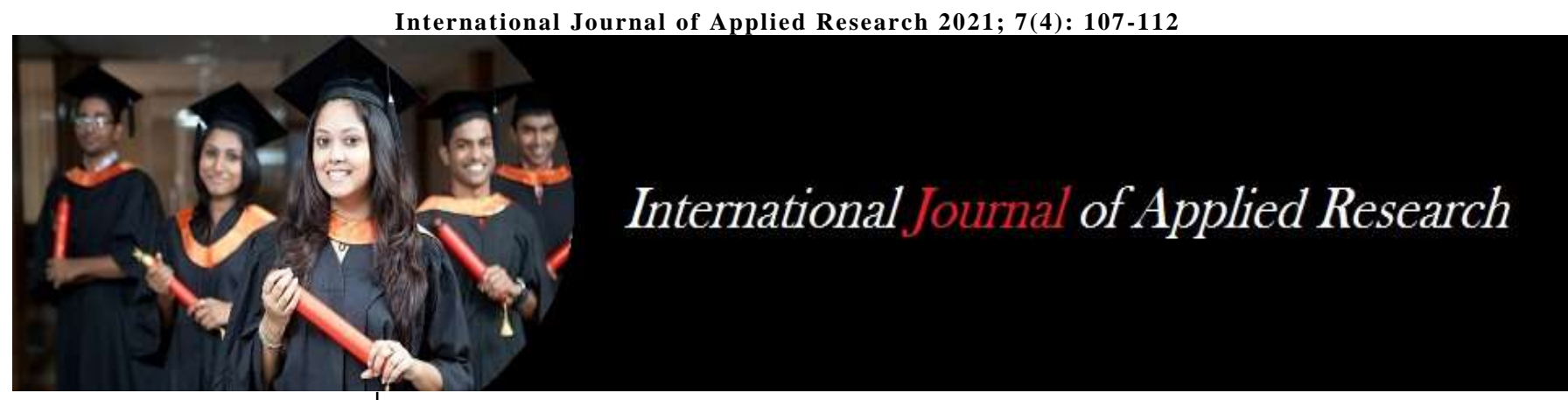

ISSN Print: 2394-7500 ISSN Online: 2394-5869 Impact Factor: 8.4 IJAR 2021; 7(4): 107-112 www.allresearchjournal.com Received: 21-02-2021 Accepted: 23-03-2021

Sarika Dewangan Assistant Professor, Department of Pediatric Nursing, Government College of Nursing, Ambikapur, Chhattisgarh, India

\section{A pre experimental study to assess the effectiveness of planned teaching program regarding essential new born care on knowledge of post natal mothers in selected hospital of Durg Chhattisgarh}

\section{Sarika Dewangan}

DOI: https://doi.org/10.22271/allresearch.2021.v7.i4b.8467

\section{Abstract}

Introduction: Essential new born care is most important at birth. New born care is the term given to a new born baby from the time of birth up to 28 days of life. Its included essential new born care include immediate basic care of neonate and routine care of neonate. Immediate basic care of newborn of the newborn at birth included maintenance of temperature, establishment of open airway, initial of breathing and maintenance of circulation. Daily routine care of neonates include warmth, breast feeding, skin care, baby bath, care of eye, clothing of baby, general care, observation, weight recording, immunization, follow up and advice.

Methods research approach: Evaluative research approach. Research design, pre experimental research design (one group pre text post text design). The conceptual framework based of "conceptual Framework based on modified system model. The setting for this study was the selected areas of District hospital Durg, Chhattisgarh. The tools developed which include,

Section 1: Socio demographic data containing sample characteristics would be analyzed using frequency and percentage.

Section II: Mean median slandered deviation and mean percentage of pre test and post test knowledge scores would be computed.

Section III: The significant difference between the mean retest and pos t test knowledge score would be calculated using paired $t$ test.

Section IV: The association between post test knowledge with selected demographic variables would be determined by the chi- square test.

Tools validity was done and tools found reliable, study found feasible after pilot study.

Result: it has been observed that in this study pretest and posttest design was used. The population for the present study comprised post natal mothers of seleted hospitals Durg. Total 40 samples were taken. sample was collected through the use of purposive sampling technique. To ensure reliability of tool data of the structured knowledge questionnaire was analyzed by split half method and the reliability coefficient was calculated through using spearman Brown prophecy formula. The reliability coefficient of the tool was found to be $r=0.816$. Hence the tool was found to be valid, reliable and feasible.

Section 1: Socio demographic data.

Section II: Assess the level of pre test and post test knowledge on post natal mothers regarding new born care

Section III: Evaluate effectiveness of planed teaching program by comparing pre and post test knowledge score.

Section IV: The association between post test knowledge with selected demographic variables.

Conclusion: The study findings showed that there was significant increase in the knowledge of post natal mothers after giving of planned teaching programme regarding new born care. Hence it was concluded that planned teaching programme has been an effective method to increase knowledge of post natal others regarding new born care.

Keywords: Knowledge, effectiveness, new born care, post natal mother

\section{Introduction}

Doing what is best for the baby is our biggest priority.' New born care is the term given to a new born baby from the time of birth up to 28 days of life. Its included essential new born care include immediate basic care of neonate and routine care of neonate.
Sarika Dewangan

Assistant Professor,

Department of Pediatric

Nursing, Government College

of Nursing, Ambikapur,

Chhattisgarh, India 
Immediate basic care of newborn of the newborn at birth included maintenance of temperature, establishment of open airway, initial of breathing and maintenance of circulation. Daily routine care of neonates include warmth, breast feeding, skin care, baby bath, care of eye, clothing of baby, general care, observation, weight recording, immunization, follow up and advice.

Cry after birth is not really the first breath of life because around 20weeks of gestation, fetus starts making relatively rapid ( 80 to $120 / \mathrm{min})$ and ineffective respiratory movements. Basic care of normal newborn babies, it is desirable to keep the normal term babies with their mothers rather than a separate nursery. Rooming -in promotes better emotional rapport between the mothers and baby. The mothers can participate in the nursing care of her baby. This infuses self-confidence in her and reduces demands on nursing personnel. Cross infection in prevented and breast feeding is established easily.

\section{Research design}

In the present study one group pre test and post test design was contended appropriate to assess the effectiveness of planned teaching Programme on knowledge of post natal mothers regarding essential new born care.

\section{Research setting}

The present study was conducted in District hospital Durg Chhattisgarh.

\section{Population}

The present study target population comprises the post natal mothers at District hospital Durg in Chhattisgarh.

\section{Sample}

In the present study the samples are post natal mothers, admitted in selected District hospital Durg.

\section{Sample size}

The total sample is 40 post natal mothers in selected District hospital Durg.

\section{Sample technique}

Purposive sampling technique was used for selecting 40 post natal mothers were taken for the study.

\section{Criteria for selection of sample \\ Inclusion Criteria}

- Post natal mothers (Durg District hospital)

- Who are willing to participate in this study?

\section{Exclusion Criteria}

- Post natal mothers who are not willing to participate are excluded from the study.

- Who are not co-operative to the study?

\section{Development of tools}

The tool was constructed to assess knowledge among post natal mothers regarding essential new born care. Since there were no standardized tools available, extensive review of literature i.e.; books, journals, articles, experts' opinion \& the investigators professional experience with questionnaire on the essential new born care provided the basis for the construction of the structured teaching, questionnaire and these self-structured teaching is used to improve knowledge among post natal mothers.

\section{Description of tools}

The self-structured questionnaire is used for the data collection composed of three parts.

Parts I: These section deals with socio demographic variable consisted of 8 items such as Age, Religion, educational status of mothers, occupational status of mother's family monthly income, type of family, parity and area of antenatal care.

Part II: These section consisted of 36 knowledge items covering following content of areas:

$\begin{array}{lll}\text { 1. Newborn } & -5 \\ \text { 2. Immediate care of Newborn } & -3 \\ \text { 3. Daily routine care of newborn } & -10 \\ \text { 4. Breast feeding } & -12 \\ \text { 5. Hypothermia } & -3 \\ \text { 6. Immunization } & -3\end{array}$

All questions were multiple choice question type and having only one correct answer and correct answer carries a score of one mark and wrong answer scores zero.

\section{Validity}

The tools and content were given to experts. Based on the suggestions given by the evaluators. After considering the experts suggestions and modification, the tools was finalized.

\section{Reliability of the tool}

In order to establish the reliability of the tools it was administered to 6 postnatal mothers in District hospital, the split half method was used to test the reliability of tools. Knowledge questionnaires was calculated by used Karl Pearson's co-relation co-efficient formula, the value was $\mathrm{r}=$ 0.816 knowledge questionnaire was found to be reliable. The tool was found to be statistically reliable for the present study.

\section{Ethical consideration}

- The research problem and objectives were approved by the research committee.

- Due permission from authority was sought and obtained.

- Informed written consent was taken from the participants,

- Anonymity of the participants was ensured.

- Confidential of the data was maintained.

\section{Plan for data collection}

Analysis of the data was done in accordance with objectives. It was done by using the descriptive $\&$ inferential statistics i.e.; calculating $\%$, mean score, mean percentage, standard deviation, co-relation coefficient test used to identify the significant association of post natal mothers regarding essential new born care with selected variables \& pie \& bar diagram were used to depict the findings.

Section 1: Socio demographic data containing sample characteristics would be analyzed using frequency and percentage. 
Section II: Mean median slandered deviation and mean percentage of pre test and post test knowledge scores would be computed.

Section III: The significant difference between the mean pretest and post test knowledge score would be calculated using paired $t$ test.

Section IV: The association between post test knowledge with selected demographic variables would be determined by the chi- square test.

\section{Pilot study}

Pilot study was conducted from $7^{\text {th }}$ January 2012 in Distic hospital Durg, Chhattisgarh. To ensure validity and reliability of the tools. It will be administered on 6 post natal mothers who are in the selection criteria. Following steps were adopted from the study.

- Formal written permission from civil surgeon, District hospital Durg.(C.G.)

- 6 subjects were selected by purposive sampling.

- Consent taken from the subjects. A self- structured questionnaire was administered.

- On an average, time taken by subject for completing the questionnaire was in $1 / 2$ an hour.

\section{Data analysis \& interpretation}

Socio demographic data containing sample characteristics would be analyzed using frequency and percentage. Mean median slandered deviation and mean percentage of pre test and post test knowledge scores would be computed. The significant difference between the mean retest and post test knowledge score would be calculated using paired t test. The association between post test knowledge with selected demographic variables would be determined by the chisquare test.

Section I: Distribution of subjects according to demographic variable.

Age distribution of post natal mothers that maximum number $(50 \%)$ belong to the age of 20-24 year and (30\%)belong to the age of 25-28year and minimum number

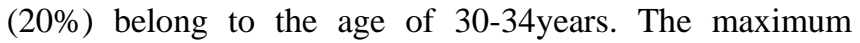
number $(67.5 \%)$ belong to the Hindu and $(17.5 \%)$ were Christian and Muslim. The maximum (57.5\%) of subject were nuclear family and $(42.5 \%)$ were live in joint family. Maximum(47.5\%) belong to educational status of mothers were primary/ middle school and $(37.5 \%)$ belong to high school, high secondary and minimum number $(7.5 \%)$ belong to illiterate and graduate. The Maximum number (65\%) belong to post natal mothers are house wife and (27.5\%) were private employee. The maximum number $(37.5 \%)$ belong to monthly family income of 5001-8000Rs/ and $(30 \%)$ were $<5000$ and $8001-10.000 \mathrm{Rs} /$ and minimum number $(7.5 \%)$ belong to $>10.000 \mathrm{Rs} /$.According to birth order $(52.5 \%)$ mothers of primi para and $(47.5 \%)$ were mother of multi para. The Maximum (40\%) type of antenatal care are primary health care and $(25 \%)$ are community health care, private doctor and (10\%) of no antenatal care
Hence it is concluded that maximum number of post natal mothers belong to the age group 20-24years, lives in nuclear family and most of them Hindus. Majority of post natal mothers education was completed primary/ middle school and monthly family income of postnatal mother is 5001$8001 /$ Rs. Most of them house wife and primi para and most of them taken primary health care.

Section II: To assess the pre-test and post test knowledge of post natal mothers regarding essential new born care.

$\mathrm{H} 1$ the mean post test knowledge score of post natal mothers regarding essential newborn care in greater than the mean pre test knowledge score at $p<0.05$.

Ho there will be no different between pre test and post test knowledge score of post natal mothers regarding essential new born care at $p>0.005$ level of knowledge questionnaires.

Table 1: Each area wise pretest and posttest percentage of post natal mothers, knowledge on essential newborn care

\begin{tabular}{|c|c|c|c|c|c|c|}
\hline \multirow{2}{*}{$\begin{array}{c}\text { Knowledge } \\
\text { related to }\end{array}$} & \multirow{2}{*}{$\begin{array}{c}\text { No. Of } \\
\text { questions }\end{array}$} & $\begin{array}{c}\text { Min } \\
\text { Max } \\
\text { score }\end{array}$ & \multicolumn{2}{|c|}{ Preatest } & \multicolumn{2}{|c|}{ Posttest } \\
\hline New born & 5 & $0-5$ & $2.55 \pm 1.28$ & $51.0 \%$ & $4.25 \pm 0.87$ & $85.0 \%$ \\
\hline $\begin{array}{c}\text { Immediate } \\
\text { basic care }\end{array}$ & 3 & $0-3$ & $1.68 \pm 0.76$ & $56.0 \%$ & $2.23 \pm 0.62$ & $74.3 \%$ \\
\hline $\begin{array}{c}\text { Daily routine } \\
\text { care }\end{array}$ & 10 & $0-10$ & $4.55 \pm 2.34$ & $45.5 \%$ & $8.25 \pm 1.15$ & $82.5 \%$ \\
\hline $\begin{array}{c}\text { Breast } \\
\text { feeding }\end{array}$ & 12 & $0-12$ & $4.88 \pm 2.78$ & $40.7 \%$ & $9.50 \pm 1.22$ & $79.2 \%$ \\
\hline Hypothermia & 3 & $0-4$ & $1.45 \pm 0.88$ & $48.3 \%$ & $2.48 \pm 0.55$ & $82.7 \%$ \\
\hline Immunization & 3 & $0-3$ & $1.60 \pm 0.74$ & $53.3 \%$ & $2.42 \pm 0.55$ & $80.7 \%$ \\
\hline Overall & 36 & $0-36$ & $16.70 \pm 4.79$ & $46.4 \%$ & $29.13 \pm 2.00$ & $80.9 \%$ \\
\hline
\end{tabular}

Postnatal mothers pretest and post test percentage of knowledge on essential newborn care. In pre test they are having maximum knowledge in immediate basic care (56\%) and minimum knowledge in Breast feeding (40.7\%), on an average they are having $46.4 \%$ of knowledge in newborn daily routine care, hypothermia and immunization. In post test they are having maximum knowledge in new born $(85.0 \%)$ and minimum knowledge in Immediate basic care $(74.3 \%)$, On an average they are having $80.9 \%$ of knowledge in daily routine care, breast feeding, breast feeding, hypothermia and immunization.

Hence it is concluded that in pre test, post natal mothers having maximum knowledge in area of immediate care of essential new born care and in post test, post test mothers having maximum knowledge in area of new born

Section III: To compare the pre-test and post test knowledge of post natal mothers regarding essential new born care.

H1 the mean post test knowledge score of post natal mothers regarding essential newborn care in greater than the mean pre test knowledge score at $p>0.05$.

Ho there will be no different between pre test and post test knowledge score of post natal mothers regarding essential new born care at $p>0.005$ level of knowledge questionnaires. 
Table 2: Comparison of each area wise knowledge score

\begin{tabular}{|c|c|c|c|}
\hline Knowledge & Pretest & Posttest & Student's paired t-test \\
\hline New born & $2.55 \pm 1.28$ & $4.25 \pm 0.87$ & $\mathrm{~T}=7.22 \mathrm{P}=0.001 * * * \mathrm{DF}=39$ significant \\
\hline Immediate basic care & $1.68 \pm 0.76$ & $2.23 \pm 0.62$ & $\mathrm{~T}=4.64 \mathrm{P}=0.001 * * * \mathrm{DF}=39$ significant \\
\hline Daily routine care & $4.55 \pm 2.34$ & $8.25 \pm 1.15$ & $\mathrm{~T}=10.32 \mathrm{P}=0.001 * * * \mathrm{DF}=39$ significant \\
\hline Breast feeding & $4.88 \pm 2.78$ & $9.50 \pm 1.22$ & $\mathrm{~T}=9.26 \mathrm{P}=0.001 * * * \mathrm{DF}=39$ significant \\
\hline Hypothermia & $1.45 \pm 0.88$ & $2.48 \pm 0.55$ & $\mathrm{~T}=6.32 \mathrm{P}=0.001 * * * \mathrm{DF}=39$ significant \\
\hline Immunization & $1.60 \pm 0.74$ & $2.42 \pm 0.55$ & $\mathrm{~T}=6.68 \mathrm{P}=0.001 * * * \mathrm{DF}=39$ significant \\
\hline * Significant at $\mathrm{P} \leq 0.05 * *$ highly significant at $\mathrm{P} \leq 0.01 * * *$ very high significant at $\mathrm{P} \leq 0.001$
\end{tabular}

New born, in pretest, postnatal mothers are having 2.55 knowledge score and after planned teaching programme they are having 4.25 knowledge score. The difference is 1.70 score. It is a large difference. Immediate basic care, In pretest, postnatal mothers are having 1.68knowledge score and after planned teaching programme they are having 2.23 knowledge score. The difference is 0.55 score. Daily routine care, in pretest, postnatal mothers are having 4.55 knowledge score and after planned teaching programme they are having 8.25 knowledge score. The difference is 3.70 score. Breast feeding_in pretest, postnatal mothers are having 4.88 knowledge score and after planned teaching programme they are having 9.50 knowledge score. The difference is 4.63score. Hypothermia_In pretest, postnatal mothers are having 1.45 knowledge score and after planned teaching programme they are having 2.48 knowledge score. The difference is 1.03 score. Immunization In pretest, postnatal mothers are having 1.60 knowledge score and after planned teaching programme they are having 2.42 knowledge score. The difference is 0.82 score. There are a large difference. This difference is statistically significant. Statistical significance was calculated by using student's paired ' $t$ ' test.

Hence it is concluded that post natal mothers having more knowledge after giving planned teaching programme in all to care of new born.
Table 3: Comparison of overall knowledge score

\begin{tabular}{|c|c|c|c|}
\hline & No. Of mothers & Mean \pm SD & Student's paired t-test \\
\hline \begin{tabular}{|l|} 
Pretest \\
\end{tabular} & 40 & $16.70 \pm 4.79$ & $\mathrm{~T}=17.75 \mathrm{P}=0.001 * * *$ \\
\hline Posttest & 40 & $29.13 \pm 2.00$ & $\mathrm{DF}=39$, significant \\
\hline
\end{tabular}

The comparison of pre-test knowledge score with post- test knowledge mean score. There was significant difference between pre-test and post-test knowledge mean score. In pretest, post natal mothers are having 16.70 score and in post test, post natal mothers are having 29.13 score. Difference is 12.43 score. The difference between pretest and posttest knowledge score is large and it is statistically significant. Differences between pretest and posttest score was analyzed using paired t-test. These result indicates that post-test knowledge mean score was higher than the pre-test knowledge mean score at p0.05levels.

Hence, the null hypothesis which states that there will be no significant difference between pre-test and post test knowledge mean score at p0.05levels is rejected and alternative hypothesis is accepted.

To assess the effectiveness of planned teaching programme regarding essential new born care.

Table 4: Effectiveness of planned teaching progrmme

\begin{tabular}{|c|c|c|c|c|}
\hline & Min -Ma x Score & Mean Knowledge Score & \% of Knowledge Score & \% of Knowledge gain \\
\hline Pretest & $0-36$ & 16.70 & $46.4 \%$ & \multirow{2}{*}{$34.5 \%$} \\
\hline Posttest & $0-36$ & 29.13 & $80.9 \%$ & \\
\hline
\end{tabular}

The effectiveness of the planned teaching programme. Considering the overall aspects, parents are gained 34.5 percent more knowledge after the administration of planned teaching programme.

Hence it is concluded 33.5percent of knowledge gain is the benefit of this study, which indicates the effectiveness of planned teaching programme.

Section IV: To associate post test knowledge of post natal mothers with selected demographic variables.

The association between post test knowledge with demographic variables such as - age, religion, type of family, educational status of mothers, monthly family income, parity and area of ante natal care. The significance of the association between them was analyzed by the chisquare test. The calculated value of chi square for age of post natal mothers $7.21(\mathrm{p}=0.02)$ which shows significant association with knowledge level. The calculated value of chi square for religion of post natal mothers $0.57(\mathrm{p}=.75)$ which shows not significant association with knowledge level. Calculated value of chi square for type of family of post natal mothers $0.01(\mathrm{p}=0.89)$ at $5 \%$ level of significant, which shows not significant association with post natal mothers. The calculated value of chi square for educational status of post natal mothers $6.12(\mathrm{p}=0.05)$ at $5 \%$ level of significant, which shows significant association with knowledge level. The calculated value of chi square for occupational status of post natal mothers $0.32(\mathrm{p}=0.85)$ at $5 \%$ level of significant, which shows not significant association with knowledge level. Calculated value of chi square for family monthly income of post natal mothers $1.10(\mathrm{p}=0.78)$ at $5 \%$ level of significant, which shows not significant association with knowledge level. As per parity of post natal mothers chi square value is $1.38(\mathrm{p}=0.24)$ at $5 \%$ level of significant, there was not significant association with knowledge level. As per area of antenatal care chi square value is $7.38(\mathrm{p}=0.02)$ at $5 \%$ level of significant, there was significant association between the area of antenatal care and knowledge level.

Hence it is concluded that there was significant association between knowledge score with age, educational status of mothers and area of ante natal care. 


\section{Conclusion}

On the basis of findings of the study following conclusion were drawn.

- The pre test knowledge score of the post natal mothers revealed that there was knowledge deficit regarding essential new born care.

- The planned teaching programme was effective in enhancing the knowledge of post natal mothers regarding essential new born care.

- Paired " $\mathrm{t}$ " test revealed that the pre test and post test knowledge score of post natal mothers was significant higher $(\mathrm{t}=\mathrm{p}=0.001)$.

- There was significant association between the age and area of ante natal care of post test knowledge score and demographic variables.

\section{Limitations}

1. The study lacks randomization due to limited time, purposive sampling was done from selected area in District Hospital Durg (C.G) which restricts the generalization of the study.

2. The size of the sample studied was only 40 post natal mothers hence it was difficult to make broad organization.

3. The time span of the study was short.

4. This study is limited to those who are willing to participate in the study.

5. The structured knowledge questionnaire was developed as no standardized tool was available.

\section{Recommendations}

1. This study can be replicated on a large sample there by findings can be generalized for larger section of the health care facilities to cover a larger population of health care team.

2. A Similar study can be carried out by using other teaching strategies. e.g instructional module, computer based learning and video assisted teaching. Similar study can be replicated to see the retention of knowledge of post Natal mothers towards essential new born care.

\section{Acknowledgement}

None can comprehend the depth of gratitude I have towards my GOD for his abundant grace and faithfulness during the course of the study and completion of this work. This study would not have been possible without the constant encouragement, inspiration and valuable support of a number of persons. The investigator is profoundly thank full to all of them. I extend my sincere thanks to Dr. Rajesh Dixit, director of Shreyas College of nursing, Bhilai, for his expert's guidance and facilities provides in the institution, helping me to undertake the course. My whole hearted gratitude to Prof. Mrs. Rachana Gupta, M.Sc. Nursing (MCH), PGDCA, Principal Shreyas college of P.G. Nursing, Bhilai, for her continous guidance, sustained patience, valuable suggestions and timely support from the inception till the completion of the study. My sincere thanks to my research Guide Madam Madam Mrs. Tripti Sahu, Reader (Maternal and child health nursing) Shreyas college of Nursing Bhilai, for her valuable guidance, inspiration and useful suggestions for the successful completion of this study.
I express my sincere thanks to my co-guide Madam Mrs. Chandrakala Verma Lecturer (child health nursing) Shreyas college of Nursing Bhilai, for her expert guidance, constant encouragement and necessary help for conducting the study. My special gratitude to Madam Ms. Jyoti Thakur, Reader cum vice Principal, Shrayas College of nursing, Bhilai for her enlightening guidance. I would like to thanks Mrs. Snigdha Tiwari and Mr. Sahu. Labrarion Shreyas college of Nursing Bhilai for extending assitanc in literature review. I express my thanks to Sir A. Venkiteshvar, statistician for guiding me with statistical analysis.

I express my sincere thanks to Sir Prashant shrivastava, civil surgeon of district Hospital Durg (C.G) for his instant support and permission to conduct the study.

My sincere and whole hearted thanks to all the experts for the encouragement, support and valuable suggestions for the tool validation. My heartfelt gratitude to Mrs. Seema Chawla (M.A English) for expert editing of the study. I am highly obliged to the teaching and office staff as well as my classmates who always co-operated unconditionally and motivated me for this task. My sincere thanks to Mr. Devendra Sahu for helping with the writing of the study. I express my special gratitude towards my parents for their constant love and affection during my struggles and pain to accomplish this task. I sincere thanks to all my colleagues, friends and well-wishers for their good wishes for this study. Finally I would like to thank all the participants who made this study possible. Above all I owe my efforts and success to almighty God for his abiding grace, which made this possible.

\section{References}

1. Datta Parul. Pediatric nursing $1^{\text {st }}$ edition. Jitendra P Vij 2007, 66-75.

2. Gupta satya. Pediatric ATLAS $2^{\text {nd }}$ edition. KK gupta New delhi 2000, 75-89.

3. Singh maharban. Medical emergencies in children $3^{\text {rd }}$ edition. NK sagar New Delhi 2000, 2-5.

4. Redding Barbara A, Marlow Dorothy R. Pediatrics nursing $6^{\text {th }}$ edition. Mosby 2009.345-347.

5. Helmy FE, Bahgat RS. J Egypt Public Health Assoc 1998;73(5-6):501-18.

6. Osborne J, Havalad S. Effect of parental head circumference on that of the new born child 2006.

7. Uzma Syed. Immediate and Early Postnatal Care for Mothers and Newborns 2003.

8. Vural G, Kisa S. Umbilical cord care: a pilot study comparing topical human milk.

9. Mohammad Hussain Khan. Essential newborn care practices in hospitals verses home deliveries. Gomal Journal of medical sciences 2006.

10. Pratibha Gupta VK, Srivastava. Indian J Community Med 2010;35(1):82-85.

11. Engl N. J Med 2010;362(18):614-623.

12. Bergström A, Okong P, Ransjö-Arvidson AB. Immediate maternal thermal response to skin-to-skin care of newborn. Acta Paediatr 2007;96(5):655-8.

13. G Gurung. Practices on immediate care of newborn in the communities of Kailali district Nepal Med Coll J 2008;10(1):41-44.

14. Singhal K. Neonatal morbidity and and mortality in ICDS urban slums Indian paeditrics 1998;27(5):485488 . 
15. Bang AT, Bang RA, Baitule SB, Reddy MH, Deshmukh MD. Effect of home-based neonatal care and management of sepsis on neonatal mortality inrural Gaciroli India. J perinatal 2005;25(1):551-61.

16. Vidya K, Sharma A, Dhugel S. Effect of early motherbaby close contact over the duration of exclusive breast feeding. Nepal Med Coll J 2005;7(2):138-40.

17. Upul Senaratha, Dulitha N, Fernando Ishani Rodrigo. Newborn care at home: Effect of hospital based intervention in shrilanka 2006.

18. Vural G, Kisa S. Umbilical Cord Care: a pilot study comparing topical human milk, povidone- iodine, and dry care. Obstet Gynecol Neonatal Nurs 2006;35(1):123-8.

19. Luke C, Gary L, joanne Katzl. Risk factors for umbilical cord infection 2006;1:6.

20. Alfonzo S. Neonatal sepsis-a global problem: an overview. Mymensingh Med J 2006;15(1):108-14.

21. Nelson AM. Maternal newborn nurses experiences of in constiten professional breast feeding support 2007;60:28-29.

22. Behrman Richard E, Jenson Hal B. Paediatrics. N17th edition. Elsevier 2004;30:31.

23. Bevi Assuma. Paediatric nursing $2^{\text {nd }}$ edition. Elsevier 2010, 130-131.

24. Datta Parul. Pediatric nursing $1^{\text {st }}$ edition. Jitendra P Vij 2007, 67-75.

25. Dr. agrawaal KN. Paediatrics and neonatology. $2^{\text {nd }}$ edition. Modern publisher 2005, 30-35.

26. Dr. Dixit Rajesh. Child development $1^{\text {st }}$ edition. Gupta manish Bhopal 2006, 29-30.

27. Ghai OP. Essential Pediatrics $6^{\text {th }}$ edition. OP ghai Delhi 2004, 1-4.

28. Guha rashmi, srivastava RD. Practical newborn critical care nursing $1^{\text {st }}$ edition. Jitendra P Vij 2006, 8-9.

29. Gupta Piyush. Essential pediatric nursing. $2^{\text {nd }}$ edition. Satish kumar Jain New Delhi 2010, 19-52.

30. Hurlock Elizabeth B. Child development. $6^{\text {th }}$ edition. Tata mcgraw-hill New Delhi 1997, 100-120.

31. James Rowan Susan, Ashwill jean Weiler. Nursinf care of the children. $2^{\text {nd }}$ edition. Elsevier 2002, 116-122.

32. Mclnotosh Neil, Helms Peter, Symth rosalid. Paediatrics. $7^{\text {th }}$ edition. Elsevier 2008, 11-12.

33. Mukherjee dilip K, Nair MKC. Growth and development. $1^{\text {st }}$ edition. Jitendra P Vij 2008, 20-30.

34. Parthasarathy A, Menon MKC. Fundamentals of paediatrics. $1^{\text {st }}$ edition. Jitendra P Vij 2007, 62-66.

35. Potts Nicki L, Mandleco Barbara L. Pediatric nursing. $2^{\text {nd }}$ edition. Thomson 2007, 25-17.

36. Redding Barbara A, Marlow Dorothy R. Pediatrics nursing. $6^{\text {th }}$ edition. Mosby 2009, 345-347.

37. Singh Jacob. Pediatric Nursing. $2^{\text {nd }}$ edition. NR Brothers Indore 2003, 66-85.

38. Singh maharban. Medical emergencies in children". $3^{\text {rd }}$ edition. NK Sagar New Delhi 2000, 2-5.

39. Singh mahaeban. Care of the new born. $6^{\text {th }}$ edition. Narinder K Sagar New Delhi 2004, 94-95.

40. Taeusch William H, Ballard Roberta A. Avery`s diseases of the newborn. $8^{\text {th }}$ edition. Elsevier 2005, 1-5.

41. Timby Barbara K, Smith nancy E. Care of adult and children. $1^{\text {st }}$ edition. Lippincott Williams \& Wilkins 2005, 67-86.

42. Viswanathan. Achar's text book of paediatrics". $3^{\text {rd }}$ edition. Orient longman Chennai 1989, 165-172. 